Aim of the study: To determine the relationship between the interval from surgery to initiation of radiation therapy (ISRT) and prognostic factors, such as age, performance status, tumour location, extent of surgical resection and tumour histology in patients with malignant gliomas.

Materials and methods: From 1995 to 2005, 308 adults patients with supratentorial malignant gliomas (198 glioblastomas, and 110 anaplastic astrocytomas) received postoperative radiotherapy with radical intent. A total tumour dose of 60 Gy in 30 fractions in 6 weeks was delivered. ISRT varied from 15 to 124 days, with median time of 37 days, and it was a cut-off value to assess the results. The end point in our study was two-year overall survival.

Results: The two-year overall survival rate in the whole group was $17 \%$, with $24 \%$ for patients with ISRT value $\leq 37$ days, and $14 \%$ for patients with an interval longer than 37 days $(p=0.042)$.

Univariate analysis showed that delayed initiation of radiotherapy influenced the outcome of patients with glioblastoma older than 40 years, and with other than frontal location of tumour. Two-year overall survival rates for ISRT $\leq 37$ days were $15 \%, 18 \%$ and $22 \%$ respectively, compared to $8 \%, 4 \%$ and $11 \%$ for ISRT > 37 days. In a multivariate analysis (Cox's model) the only variables that were significantly associated with worse survival were older age and ISRT prolonged for more than 37 days. Conclusion: The study showed longer than 37 days waiting time from surgery to initiation of radiotherapy to be a significant predictor of overall survival for adult patients with malignant supratentorial gliomas.

Key words: malignant gliomas, radiotherapy, timing of radiation, prognostic factors.

\section{Prognostic value of the interval from surgery to initiation of radiation therapy in correlation with some histo- clinical parameters in patients with malignant supratentorial gliomas}

\author{
Bogdan Gliński, Jacek Urbański, Marcin Hetnał, Krzysztof Małecki, \\ Magdalena Jarosz, Anna Mucha-Małecka, Agnieszka Chrostowska, \\ Ewa Jakubowicz, Beata Frączek-Błachut, Paweł Dymek
}

Department of Head and Neck Cancer, Centre of Oncology Maria Skłodowska-Curie Memorial Institute, Cracow Branch, Kraków, Poland

\section{Introduction}

Malignant supratentorial gliomas (MSG) are the most common primary brain tumours in adults. Recently standard treatment consists of maximum safe surgical excision followed by external beam radiotherapy with concomitant and adjuvant chemotherapy with temozolomide. Commonly radiotherapy should start 3-4 weeks after surgery, but in our institution, due to resource and staffing constraints the waiting time for MSG patients fluctuated widely, and very often was much longer than four weeks. The relationship between the delay in radiotherapy and the outcome of patients has been explored in several tumour types and especially in head and neck cancers [1-7], but only a few communications have specifically addressed the delayed initiation of irradiation for MSG [8-17]. The current investigation was undertaken to explore this relationship by analysing the database of our centre, which provides prolonged follow-up of patients with MSG treated with postoperative irradiation.

The purpose of our data is to study the effect on survival of the interval from surgery to initiation of radiotherapy (ISRT), and appraise whether ISRT influenced outcome for patients with MSG, in correlation with different pathoclinical features (patient's age and gender, Karnofsky performance status, tumour's histology and location, extent of resection).

\section{Materials and methods}

The study population was derived from neurosurgical centres which referred patients to the Maria Skłodowska-Curie Memorial Centre in Kraków for radiation therapy. Surgery consisted of as complete tumour removal as possible. All surgical specimens were evaluated, by the same pathologist, according to the WHO classification as described by Louis et al. [18]. Between January 1997 and December 2007, 308 unselected patients with MSG were postoperatively irradiated. The tumour dose of $60 \mathrm{~Gy}$ in 30 fractions in six weeks was delivered. The ISRT varied from 15 to 124 days with a median value of 37 days, and this timing is taken in our study as a cut-off value for ISRT. We determined two ISRT values: ISRT1 $\leq 37$ days, and ISRT2 > 37 days. Neurological function and Karnofsky performance status (KPS) [19] of each patient were carefully recording before starting radiotherapy as well as immediately after termination of treatment and on each follow-up examination. The end point for this study was two-year overall survival. Patients were checked monthly after completion of therapy for one year and every 3 months thereafter. Both univariate and multivariate analysis were performed. Cox's proportional hazard mod- 
Table 1. Patient characteristics by the ISRT values

\begin{tabular}{|c|c|c|c|c|}
\hline \multirow[t]{2}{*}{ Characteristics } & \multicolumn{2}{|c|}{ ISRT1 $(n=156)$} & \multicolumn{2}{|c|}{ ISRT2 $(n=152)$} \\
\hline & $n$ & $\%$ & $n$ & $\%$ \\
\hline \multicolumn{5}{|l|}{ Gender } \\
\hline Male & 82 & 52 & 90 & $59^{*}$ \\
\hline Female & 74 & 48 & 62 & 41 \\
\hline \multicolumn{5}{|l|}{ Age (years) } \\
\hline 40 or less & 44 & 28 & 39 & 26 \\
\hline More than 40 & 112 & 72 & 113 & 74 \\
\hline \multicolumn{5}{|l|}{ Karnofsky status } \\
\hline 60 or more & 49 & 32 & 47 & 31 \\
\hline Less than 60 & 107 & 68 & 105 & 69 \\
\hline \multicolumn{5}{|l|}{ Resection } \\
\hline Total & 47 & 30 & 47 & 31 \\
\hline Partial & 109 & 70 & 105 & 69 \\
\hline \multicolumn{5}{|l|}{ Histology } \\
\hline Glioblastoma & 94 & 60 & 94 & 62 \\
\hline Anaplastic astrocytoma & 62 & 40 & 58 & 38 \\
\hline \multicolumn{5}{|l|}{ Tumour location } \\
\hline Frontal & 50 & 32 & 56 & 37 \\
\hline Others & 106 & 67 & 96 & 63 \\
\hline
\end{tabular}

ISRT - interval from surgery to irradiation. ISRT1 $\leq 37$ days, ISRT2 > 37 days. ${ }^{*}$ There is some disparity between the patient characteristics with more males and relatively more frontal tumours in the ISRT2 group.

Table 3. Univariate analysis

\begin{tabular}{|c|c|c|}
\hline Characteristics & $\begin{array}{c}\text { 2-year overall } \\
\text { survival (\%) }\end{array}$ & $P$ \\
\hline $\begin{array}{l}\text { Age (years) } \\
40 \text { or less } \\
\text { More than } 40\end{array}$ & $\begin{array}{c}40 \\
9\end{array}$ & 0.000 \\
\hline $\begin{array}{l}\text { Gender } \\
\text { Male } \\
\text { Female }\end{array}$ & $\begin{array}{l}16 \\
19\end{array}$ & 0.33 \\
\hline $\begin{array}{l}\text { Karnofsky status } \\
60 \text { or more } \\
\text { Less than } 60\end{array}$ & $\begin{array}{l}17 \\
17\end{array}$ & 0.54 \\
\hline $\begin{array}{l}\text { Resection } \\
\text { Total } \\
\text { Partial }\end{array}$ & $\begin{array}{l}18 \\
17\end{array}$ & 0.56 \\
\hline $\begin{array}{l}\text { Histology } \\
\text { Glioblastoma } \\
\text { Anaplastic astrocytoma }\end{array}$ & $\begin{array}{l}10 \\
30\end{array}$ & 0.000 \\
\hline $\begin{array}{l}\text { Tumour location } \\
\text { Frontal } \\
\text { Other than frontal }\end{array}$ & $\begin{array}{l}22 \\
16\end{array}$ & 0.049 \\
\hline $\begin{array}{l}\text { ISRT } \\
\text { ISRT1 } \\
\text { ISRT2 }\end{array}$ & $\begin{array}{l}24 \\
14\end{array}$ & 0.042 \\
\hline
\end{tabular}

el was applied to evaluate the strength of influence of examined variables and was expressed as relative risk of hazard (RRH). The values were standardized so that the final model contains only features which are significant for shaping the probability of survival $(p \leq 0.05)[20,21]$.

The distribution of patient characteristics by the ISRT values is given in Table 1.
Table 2. Results according to ISRT values

\begin{tabular}{|c|c|c|c|}
\hline Characteristics & $\begin{array}{l}\text { year overall } \\
\text { ISRT1 (\%) }\end{array}$ & $\begin{array}{l}\text { survival } \\
\text { ISRT2 (\%) }\end{array}$ & $P$ \\
\hline \multicolumn{4}{|l|}{ Age (years) } \\
\hline 40 or less & 45 & 39 & 0.32 \\
\hline More than 40 & 18 & 4 & 0.003 \\
\hline \multicolumn{4}{|l|}{ Gender } \\
\hline Male & 20 & 14 & 0.12 \\
\hline Female & 29 & 15 & 0.18 \\
\hline \multicolumn{4}{|l|}{ Karnofsky status } \\
\hline 60 or more & 25 & 12 & 0.467 \\
\hline Less than 60 & 23 & 16 & 0.519 \\
\hline \multicolumn{4}{|l|}{ Resection } \\
\hline Total & 35 & 13 & 0.06 \\
\hline Partial & 22 & 15 & 0.15 \\
\hline \multicolumn{4}{|l|}{ Histology } \\
\hline Glioblastoma & 15 & 8 & 0.036 \\
\hline Anaplastic astrocytoma & 35 & 28 & 0.91 \\
\hline \multicolumn{4}{|l|}{ Tumour location } \\
\hline Frontal lobe & 28 & 22 & 0.64 \\
\hline Others & 22 & 11 & 0.009 \\
\hline
\end{tabular}

Table 4. Multivariate analysis (Cox's model)

$\begin{array}{lcc}\text { Characteristics } & \text { RRH } & \text { P } \\ \text { Age } & & \\ 40 \text { years or less } & 1 & \\ \text { More than } 40 & 2.78 & 0.000 \\ \text { ISRT } & & \\ \text { ISRT1 } & 1 & \\ \text { ISRT2 } & 1.54 & 0.007\end{array}$

RRH - relative risk of hazard

\section{Results}

The two-year overall survival in the whole group of 308 MSG patients was 17\%, and it was 10\% for glioblastomas and $30 \%$ for anaplastic astrocytomas. Corresponding survival rates for ISRT1 and ISRT2 were 15\%, 8\% and 35\%, 28\% respectively. The results of treatment according to the ISRT values are presented in Table 2.

Results of univariate and multivariate analysis are given in Table 3 and 4.

In our study the univariate analysis showed that delayed initiation of radiotherapy influenced the outcome of patients with glioblastoma older than 40 years, and in other than frontal location of tumour. Two-year overall survival rates for ISRT $\leq 37$ days were $15 \%, 18 \%$ and $22 \%$ respectively, compared to $8 \%, 4 \%$ and $11 \%$ for ISRT > 37 days. In a multivariate analysis (Cox's model) the only variables that were significantly associated with worse survival were older age (more than 40 years), and ISRT prolonged for more than 37 days.

\section{Discussion}

Fractionated external beam radiotherapy is an important component of standard treatment for MSG. In every therapy schedule comprising postoperative irradiation, it seems of importance to determine the optimum mo- 
ment for starting irradiation. The recent technological progress has paradoxically lengthened the interval from surgery to initiation of radiotherapy (ISRT). Complex treatment planning and procedures associated with providing proper radiation therapy quality (quality assurance) require much more time from a radiotherapist and a medical physicist. At the same time the number of irradiated patients has also increased because of the increased number of indications for this treatment. Longer waiting times can cause anxiety in both patients and physicians, who may be concerned about tumour progression before treatment commences. Due to the lack of evidence as to the effect of longer ISRT, it has been difficult to convince funding bodies of the extent of this problem. It may seem that in the case of MSG, which are rapidly growing tumours, the ISRT should be as short as possible. Nevertheless, the literature provides conflicting data on this theme.

Burnet et al. devised a complex mathematical model using pathological and radiobiological concepts, based on survival data from 154 glioblastoma patients treated with radiation therapy after surgery. Timing was taken from the date of the first oncology consultation rather than surgery. Their model showed a steep in median survival after a delay of 40 days. The deleterious effect of delay of survival became more marked if patients intended for treatment were also included [9]. In a study from Westmead Hospital (Sydney) in cooperation with the National Health Service and the Medical Research Council, the authors used multivariate analysis to assess the effect of radiotherapy delay on survival in a group of 182 patients with MSG. They found a significant relationship between survival and the time from first assessment in the radiotherapy. The risk of death increased $2 \%$ for every day of delay. A delay of 4 weeks from the time of referral resulted in a 10-week reduction in median survival. However, no statistically significant relationship between survival and the time from surgery to the start of radiotherapy was found. An interesting finding of the authors was the fact that older patients, those with poorer performance status, and those with less than total resection had shorter median time from presentation to radiotherapy. One could suppose this was the effect of an attempt to "compensate" for those patients' poor prognosis with "faster" postoperative irradiation [10]. Irvin et al. found that a delay in radiotherapy results in a clinically significant reduction in survival. In a group of 172 patients with MSG, time to radiotherapy after surgery varied from 7 days to over 16 weeks. Every additional week of delay until the start of radiotherapy increases the risk of death by $8.9 \%$. A 6-week delay in starting radiotherapy (from 2 weeks to 8 weeks) reduces median survival by 11 weeks. These data emphasize the importance of minimizing delays at every step in the process, including rapid histological diagnosis and reliable early communication between the neurosurgical and oncology teams [12]. Nöel et al. retrospectively analysed 94 consecutive patients with histologically proven glioblastoma postoperatively irradiated. For all patients median ISRT was 46 days. The median overall survival for patients with ISRT up to 46 days, and over this period, was 14.3 and 13.6 months respectively. The difference in survival was not statistically significant $(p=0.8)$ [14]. Similarly, Thomson et al. did not find a relationship between the ISRT and treatment outcome in a group of 40 patients with glioblastoma [15].

The above data show that lengthening of ISRT affects, more or less significantly but generally negatively, the survival of patients with MSG receiving postoperative irradiation. In this context the report from the Radiation Therapy Oncology Group (RTOG) seems to be controversial. A large number of patients (2855) with histologically confirmed supratentorial glioblastoma were included in that analysis. Four patient groups were selected based on the interval from surgery to the start of radiotherapy: $\leq 2$ weeks, 2 to 3 weeks, 3 to 4 weeks, and more than 4 weeks up to the protocol eligibility limit of 6 weeks. No decrement in survival could be identified with increasing ISRT. Median survival time was unexpectedly and significantly greater in the group with the longest interval ( $>4$ weeks) than in those with the shortest delay ( $\leq 2$ weeks): respectively, 12.5 months versus 9.2 months ( $p<0.0001)$. On multivariate analysis, with overall survival as the end point, time interval more than 4 weeks was one of the significant predictors of improved outcome. It is difficult to propose a plausible mechanism for an association between delayed therapy and improved survival in the treatment of glioblastoma. Finally, there may be a detrimental effect to the brain when treated with radiation too soon after the primary insult of surgery. Hypoxia from surgical manipulation and oedema in the immediate postoperative period may diminish radiosensitivity. It is unclear that the retrospective nature of this review allows sufficient power to exclude the possibility that delays in ISRT may have had small but clinically meaningful deleterious effects [8].

Our study suggests that longer than 37 days delay in receiving radiotherapy after surgery decreases survival of patients with malignant supratentorial gliomas. However, our data suffer from the well-known shortcomings and potential bias of a retrospective study.

\section{References}

1. Brouha XD, Op De Coul B, Terhaard CH, Hordijk GJ. Does waiting time for radiotherapy affect local control of T1NOMO glottic laryngeal cancer? Clin Otolaryngol 2000; 25: 215-8.

2. Chen Z, King W, Pearcey R, Kerba M, Mackillop WJ. The relationship between waiting time for radiotherapy and clinical outcomes. Radiother Oncol 2008; 87: 3-16.

3. Huang J, Barbera L, Brouwers M, Browman G, Mackillop WJ. Does delay in starting treatment affect the out comes of radiotherapy? A systematic review. J Clin Oncol 2003; 21: 555-63.

4. MacKillop WJ. Killing time: the consequences of delays in radiotherapy. Radiother Oncol 2007; 84: 1-4.

5. Primdhall H, Nielsen AL, Larsen S, et al. Changes from 1992 to 2002 in the pretreatment delay for patients with squamous cell carcinoma of larynx or pharynx: a Danish nationwide survey from DAHANCA. Acta Oncol 2006; 45: 156-61.

6. Schlienger M, Chauvel C, Roujeau J, et al. Délais et retards á la radiothérapie: réflexion á propos de trois types de tumeurs. Cancer Radiothér 2005; 9: 590-601.

7. Waaijer A, Terhaard CH, Dehnad H, Hordijk GJ, van Leeuwen MS, Raaymakers CP, Lagendijk JJ. Waiting for radiotherapy: consequences of volume increase for the TCP in oropharyngeal carcinoma. Radiother Oncol 2003; 66: 271-6.

8. Blumenthal DT, Won M, Mehta MP, Curran WJ, Souhami L, Michalski JM, Rogers CL, Corn BW. Short delay in initiation of radiotherapy may not affect outcome of patients with glioblastoma: a secondary 
analysis from the radiation therapy oncology group database. J Clin Oncol 2009; 10: 733-9.

9. Burnet NG, Jena R, Jefferies SJ, Stenning SP, Kirkby NF. Mathematical modeling of survival glioblastoma patients suggest a role of radiotherapy dose escalation and predicts poorer outcome after delay to start treatment. Clin Oncol 2006; 18: 93-103.

10. Do V, Gebski V, Barton MB. The effect of waiting for radiotherapy for grade III/IV gliomas. Radiother Oncol 2000; 57; 131-6.

11. Gonzalez-SanSegundo C, Santos-Miranda JA, Cuesta-Alvaro P. Comment on: The effect of waiting for radiotherapy for grade III/IV gliomas. Radiother Oncol 2001; 60: 333-6.

12. Irwin C, Hunn M, Purdie G, Hamilton D. Delay in radiotherapy shortens survival in patients with high grade gliomas. J Neurooncol 2007; 85: 339-43.

13. Lopez S, Calugaru V, Lamproglou I, Boskos C, Taillibert S, Simon JM, Mazeron J. Les effets de la liste d'attente sur la survie des patients atteints des glioblastomes traités par irradiation. Cancer Radiother 2008; 12: 497-9.

14. Nöel G, Quentin P, Heymann S, et al. Les delais au diagnostic et á la mise en traitement n'altèrent pas les résultats des traitements delivrés aux patients atteints des glioblastomes. Cancer Radiother 2009; 13: $17-23$.

15. Thomson CL, Watterson A, Pritchard C, et al. Effects of waiting times and adjuvant radiotherapy in patients with glioblastoma multiforme. Clin Oncol 2007; 19: 47-8.

16. Gliński B, Reinfuss M. Radiothérapie post-opératoire des glioblastomes. J Eur Radiothér 1986; 7: 15-8.

17. Winkler B, Czekajska-Chebab E, Juszczyńska J, Mazurkiewicz M. Predictive value estimation of selected prognostic factors in patients with malignant cerebral astrocytomas. Onkologia Info 2007; 4: 24-31.

18. Louis DN, Ohgaki H, Wiestler OD. The 2007 WHO classification of tumours of the central nervous system. Acta Neuropathol 2007; 114: 97-109.

19. Karnofsky DA, Burchenal JM. The clinical evaluation of chemotherapeutic agents in Cancer. In: Evaluation of Chemotherapeutic Agents. MacLead (ed.). Columbia Univ Press, New York 1949; 191-205.

20. Peto R, Pike MC, Armitage P. Design and analysis of randomized clinical trials requiring prolonged observation of each patient. II. Analysis and examples. Br I Cancer 1977; 35: 1-39.

21. Cox DR. Regression models and life tables. J Royal Stat Soc, Series B. 1972; 34: 187-229.

\section{Address for correspondence}

\section{Bogdan Glińsk}

Klinika Nowotworów Głowy i Szyi

Centrum Onkologii - Instytut im. Marii Skłodowskiej-Curie

Oddział w Krakowie

ul. Garncarska 11

31-115 Kraków, Poland

tel. +48 124231049

e-mail: z5glinsk@cyf-kr.edu.pl

Submitted: $\quad 2.12 .2010$

Accepted: $\quad$ 18.01.2012 